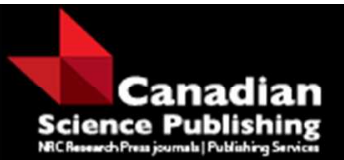

Canadian Journal of Forest Research

Revue canadienne de recherche forestière

\title{
Climate impacts on radial growth and vegetation activity of two co-existing Mediterranean pine species
}

\begin{tabular}{|r|l|}
\hline Journal: & Canadian Journal of Forest Research \\
\hline Manuscript ID & cjfr-2015-0146.R2 \\
\hline Manuscript Type: & Article \\
\hline Complete List of Authors: & $\begin{array}{l}\text { Pasho, Edmond; Faculty of Forestry Sciences, Agricultural University of } \\
\text { Tirana } \\
\text { Alla, Arben Q.; Faculty of Forestry Sciences, Agricultural University of } \\
\text { Tirana }\end{array}$ \\
\hline Keyword: & Climate, Tree ring, Vegetation indices, Pinus halepensis, Pinus pinea \\
\hline \multicolumn{2}{|c}{} \\
\hline
\end{tabular}

\section{SCHOLARONE ${ }^{m}$}

Manuscripts 
$1 \quad$ Climate impacts on radial growth and vegetation activity of two co-existing Mediterranean pine species

3

4 Edmond Pasho* and Arben Q. Alla

5 Faculty of Forestry Sciences, Agricultural University of Tirana, Kodër-Kamëz, 1029 Tirana, 6 Albania

7

8

$9 \quad$ * Corresponding author:

10 Faculty of Forestry Sciences, Agricultural University of Tirana,

11 Kodër-Kamëz 1029, Tirana, Albania.

12 Tel.: +355672295133

13 E-mail addresses: mondipasho@gmail.com; epasho@ubt.edu.al

14 
15

16

17

18

19

20

21

22

23

\section{Abstract}

Improved knowledge of the time scales at which drought stress mostly influences tree growth is crucial for the early detection of forest dieback. This study aimed at evaluating the impact of climate (temperature, precipitation) on vegetation activity (Normalized Difference Vegetation Index (NDVI), Enhanced Vegetation Index (EVI)) of Pinus halepensis Mill. and P. pinea L. mixed forest located in western Albania and assessing the drought (Standardized Precipitation Index (SPI), Standardized Precipitation Evapotranspiration index (SPEI)) calculated at different time scales (112 months) impact on radial growth (earlywood (EW), latewood (LW), tree-ring width (RW)) and vegetation activity of these species. Both vegetation indices showed negative response to August temperatures while the EVI responded positively to September precipitation. NDVI and EVI were significantly affected by the SPI in spring and late summer. All tree-ring features in P. halepensis were positively related with EVI in August whereas P. pinea LW showed significant and positive relationship with NDVI in September. Radial growth of $P$. halepensis responded significantly to both drought indices in late summer and early autumn, particularly the LW width. Contrastingly, in $P$. pinea only EW showed vulnerability mostly to the summer SPEI drought indices. These results are relevant to understand the impacts of increased drought intensity and frequency on tree radial growth and vegetation activity in a region vulnerable to climate variability.

Keywords: Climate, drought, tree-ring, Pinus halepensis, Pinus pinea, vegetation indices. 


\section{Introduction}

Climatic predictions indicate that the Mediterranean area will be affected by an increase in mean air temperature and a higher frequency of extreme climatic events (i.e. severe drought or extreme heat waves, torrential rainfall) over the twenty-first century (García-Ruiz et al. 2011; IPCC 2013). These trends towards increasing arid conditions are expected to cause frequent episodes of forest growth decline and mortality events affecting selectively tree species, trees and stands (Koepke et al. 2010; Allen et al. 2010; Sánchez-Salguero et al. 2010, 2012; Nabais et al. 2014; Sánchez-Costa et al. 2015). Therefore, uncertainties remain concerning the responses of co-existing Mediterranean pine species to climate variability, which are subjected to both water-stress and relatively high summer temperature (Cherubini et al. 2003; Sánchez-Salguero et al. 2010; Pasho et al. 2011; Sánchez-Costa et al. 2015). Understanding the response of forests to synergistic effects of temperature rise and drought is a crucial challenge, as growth and $\mathrm{CO}_{2}$ uptake are constrained to a large extent by drought (Vicente-Serrano et al. 2013).

The impacts of drought on tree growth are difficult to quantify due to lags between drought occurrence and tree response. The latter is challenged by the differences in physiological and anatomical adjustments of trees in dealing with drought (Pasho et al. 2011; Klein et al. 2013). Variations in drought duration, severity and time make it difficult to compare drought events in time and space. Therefore, when dealing with species specific responses to drought, it is essential to properly consider and quantify drought duration, severity and season in which drought occurs, as well as the time scale of tree responses. Drought effect depends not only on the amount of precipitation but also on other factors such as temperature (i.e., evaporative demand). Knowledge of the time scales at which drought stress mostly influences tree growth may be critical for the early detection of forest dieback and for identifying response patterns that determine the resistance and plasticity of tree species to drought (Vicente-Serrano et al. 2013; Dorman et al. 2015). 
The most widely used remotely sensed indices for monitoring variations in forest

59

60 productivity dynamics, as they measure canopy greenness, leaf area and canopy chlorophyll content, are the Normalized Difference Vegetation Index (NDVI) and the Enhanced Vegetation Index (EVI). The NDVI is often used as an estimator of photosynthetic active radiation (PAR) that is absorbed by the canopy (Tucker et al. 1985; Wang et al. 2004; Garbulsky et al. 2013). The EVI was developed to enhance sensitivity in high biomass regions and improve vegetation monitoring through a de-coupling of canopy background signal and a reduction in atmosphere influences (Wardlow et al. 2007; Garbulsky et al. 2013). Whereas the NDVI is chlorophyll sensitive, the EVI is more responsive to canopy structural variations, including leaf area index, canopy type, plant physiognomy and canopy architecture (Gao et al. 2000). The two vegetation indices complement each other in vegetation studies and improve upon the detection of vegetation changes and extraction of canopy biophysical parameters (Huete et al. 2002).

Several studies have analysed the dendroecology of typical Mediterranean pine species (Raventós et al. 2001; Cherubini et al. 2003; Campelo et al. 2007; Vieira et al. 2010; de Luis et al. 2011, 2013; Sarris et al. 2011; Olivar et al. 2012; Mazza and Manetti 2013; Novak et al. 2013; Piraino et al. 2013; Klein et al. 2013, 2014; Nabais et al. 2014; Dorman et al. 2015) These studies demonstrated the control of precipitation on tree-ring widths of low-elevation pine species and emphasised that water stress caused by decrease of precipitation and increase of air temperature could seriously affect tree growth of these species despite their physiological adjustments to cope with drought. These findings on tree growth responses to climate are important since the Mediterranean area, as a transitional climate zone between humid and arid regions, is particularly sensitive to climate change (Mazza and Manetti 2013). However, in western Balkan, studies on climate-growth relationships of typical Mediterranean pine species are scarce (e.g., Sarris et al. 2011; Toromani et al. 2015a) and have not considered the early detection of forest dieback by means of cumulative scale drought indices as well as the drought impact on vegetation activity. This 
83 is important since for the south eastern Europe, climate change scenarios predict increase in air 84 temperature $\left(+4^{\circ} \mathrm{C}\right)$ and decrease in precipitation $(-20 \%)$ by the end of $21^{\text {st }}$ century (Bruci 2007).

85 Therefore, in this study we focus on the effects of climatic variables (temperature, precipitation) on vegetation activity (Normalized Difference Vegetation Index (NDVI), Enhanced Vegetation Index (EVI)) of two co-existing Mediterranean pine species (Pinus halepensis Mill. and Pinus pinea L.), and on the impacts of drought (Standardized Precipitation Index (SPI), Standardized Precipitation Evapotranspiration index (SPEI)) on vegetation activity and tree radial growth (earlywood (EW), latewood (LW), tree-ring width (RW)) of these species. The purpose of this investigation is to assess the degree of influence of climate variability on vegetation activity and tree growth of $P$. halepensis and $P$. pinea. Studies considering EW and LW widths allow for better understanding the impact of seasonal water shortage on radial growth components, considering that the formation of both EW and LW are influenced by distinct climatic factors (Pasho et al. 2012).

The objectives of this study were to: $(i)$ asses the relationships between climate and vegetation activity in $P$. halepensis and $P$. pinea, (ii) test the usefulness of two multi scalar drought indices (SPI, SPEI) in identifying impacts on tree radial growth and vegetation activity in these species, (iii) determine the duration and seasonality of drought that mostly influence tree radial growth and vegetation activity.

\section{Materials and methods}

\section{Study area}

The study area is located in western Albania, within the National Park of Divjaka-Karavasta on Adriatic coastal zone (see Toromani et al. 2015a). The area is located on flat terrain and elevation about $3 \mathrm{~m}$ a.s.l. Forests are mixed, composed of $P$. halepensis Mill. and $P$. pinea L. trees where the former are more numerous than the latter (Leone et al. 2003; Miho and Witkowski 2005). The understory vegetation is rich and composed of Pistacia therebinthus L., Myrtus communis L., 
109

110 111 Eutric fluvisols. These soils are formed on alluvial deposits, characterized by a medium texture, 112 113

Juniperus oxycedrus subsp. Macrocarpa L., Agrimonia eupatoria L., Dictamnus albus L., Orchis albanica Goelz et Reinhard., etc. (Paparisto et al. 1988). The soil types are alluvial meadow and good hydraulic conductivity properties and high water holding capacity (Zdruli 1997). The climate is typical Mediterranean (temperate-warm bio-climate), characterized by hot (dry) summers and mild (wet) winters (see Toromani et al. 2015a).

\section{Climatic data and drought indices calculation}

To quantify the climatic variability in the study area we used data of mean monthly temperature and total monthly precipitation (period 1960-2013) obtained from a local meteorological station (Divjaka climate station, $40^{\circ} 59^{\prime} 33^{\prime \prime} \mathrm{N}, 1^{\circ} 32^{\prime} 25^{\prime \prime} \mathrm{E}$, elevation $4 \mathrm{~m}$ a.s.1.), located in a distance less than $5 \mathrm{~km}$ and at approximately the same altitude as the study area.

Using the monthly mean temperature and total monthly precipitation series we obtained two cumulative time scale drought indices, SPI (McKee et al. 1993) and SPEI (Vicente-Serrano et al. 2010). SPI was calculated using only precipitation data which are accumulated for various months starting from the current month and adding the preceding months up to a certain time scale (i.e. 112). The cumulative series are standardized using Pearson III distribution because it adapts well to the precipitation series at all-time scales, independently of the time scale analysed. The output is the drought index SPI with an average value of 0 and standard deviation 1. A SPI of 0 indicates precipitation corresponding to $50 \%$ of accumulated probability according to Pearson III distribution. The complete formulation of SPI following the Pearson III distribution and L-moments method for calculating parameters is described by Vicente-Serrano (2006).

The drought index SPEI was computed based on a monthly climatic water balance. The computation of the index begins with calculation of the difference between precipitation and potential evapotranspiration (D parameter) which provides a simple measure of water surplus or deficit for the analyzed month. These values are accumulated for various months following a 
135 similar approach to that for SPI. The cumulative series are standardized using the three-parameter

136 log-logistic distribution because it adapts well to the empirical frequencies of D series,

137 independently of the time scale analyzed. The output is the drought index SPEI with an average

138 value of 0 and standard deviation 1 . A SPEI of 0 indicates a value corresponding to $50 \%$ of the

139 cumulative probability of $\mathrm{D}$, according to a log-logistic distribution. The complete methodology is

140 described by Vicente-Serrano et al. (2010).

\section{Dendrochronological methods}

142 The radial growth samples were obtained from twenty $P$. halepensis and fifteen $P$. pinea dominant 143 trees randomly selected at the study area. Tree growth variability was quantified by means of 144 standard dendrochronological methods (Stokes and Smiley 1968). The cross-dating was evaluated 145 using COFECHA software (Holmes 1983) whereas the detrending and standardisation of the ring146 width series was performed with the software ARSTAN (Cook and Holmes 1984). The detrending

147 and standardization of each cross-dated ring-width series was performed to remove age-related 148 growth trends (Fritts 1976; Cook and Kairiukstis 1990). A double detrending method was applied to 149 process the series of raw data, using firstly negative linear or exponential functions and secondly 150 cubic smoothing spline functions with a $50 \%$ frequency response of 32 years to keep the high to 151 medium frequency response to climatic variability (Cook and Peters 1981). Autoregressive 152 modeling was carried out on each detrended ring-width series to remove most of the first-order 153 autocorrelation (AC1). The AC1 values ranged from 0.68 to 0.73 for P. halepensis and from 0.65 to 1540.78 for $P$. pinea (Toromani et al. 2015a). The indexed residual series of all trees were then 155 averaged using a biweight robust mean to obtain mean site residual chronologies of EW, LW and $156 \mathrm{RW}$ which were used in all analyses.

157 Further details on samples collection, measurement, data standardization and the basic statistics of 158 the chronologies can be found at Toromani et al. (2015a). The raw data series are available at the 159 ITRDB webpage (The International Tree-Ring Data Bank: www.ncdc.noaa.gov/paleo/treering.html 
160 (Toromani et al. 2015b, 2015c)).The common period 1960-2010 was selected mainly because all

161 residual chronologies showed Expressed Population Signal (EPS) values above the 0.85 threshold

162 for this interval, which is widely recognized in dendrochronological studies for accepting mean

163 growth series as being well replicated (Wigley et al. 1984). However, additional reasons were the

164 climatic data availability and the shortness of P. halepensis chronology (Fig. 1).

165

166 Remote sensing data

167 To quantify the vegetation activity at the study area we used time series of NDVI and EVI covering

168 the period 2000-2013. The dataset was obtained from the products of Moderate Resolution Imaging

169 Spectro-radiometer (MODIS 13Q1 product in HDF format, 16-day at 250-m resolution; available at

170 https://lpdaac.usgs.gov/products/modis_products table/mod13q1; $\quad$ http://glovis.usgs.gov/, H/V:

171 19/4, Lat/Long: 45.0/21.2) to provide a 14 year satellite record of monthly changes in vegetation

172 activity of pine species. Data processing included images re-projection from a Sinusoidal to a

173 WGS-84 projection and crossing them with the location of sampled forests to extract the NDVI and

174 EVI values. Considering the moderate resolution of the images and the mixture of the forest, we

175 calculated an average monthly value of NDVI and EVI for the study area and used it in further 176 analysis.

177

178 Statistical analysis

179 Correlation analyses using the Pearson coefficient were computed between the climatic series of 180 monthly mean temperatures, monthly total precipitation and the monthly (April - October because 181 of the high vegetation activity) NDVI and EVI vegetation indices from 2000 to 2013. The same 182 period was used for the analysis of the drought-vegetation indices relationships. Correlation 183 analyses were also carried out between residual chronologies and the vegetation indices for the 184 period 2000-2010 to identify potential links between them. Finally, the correlation analyses were 
185 computed to examine the relationships between drought indices (SPI, SPEI) and the residual 186 chronologies of EW, LW and RW (period 1960-2010).

187

188

\section{Results}

\section{Climate-growth relationships}

Climatic variables influenced the local vegetation activity. We found significant and negative correlation of both NDVI and EVI with August temperature $(r=0.60, P=0.023 ; r=0.64, P=$ 0.014, respectively), and positive response of EVI to precipitation on September $(r=0.68, P=$ 0.008) (Fig. 2). NDVI responded positively to the SPI at the time scale of 1 month, on April ( $r=$ $0.54, P=0.048)$, May $(r=0.59, P=0.026)$ and August $(r=0.68, P=0.007)$ whereas the EVI showed positive association with the SPI at time scale of 1 month, on May $(r=0.52, P=0.047)$ and August $(r=0.66, P=0.010)$. Both vegetation indices did not show any significant relation with the SPEI. EW, LW and RW indices of P. halepensis showed positive correlation with EVI on August ( $r$ $=0.60, P=0.039 ; r=0.68, P=0.022 ; r=0.70, P=0.016$, respectively) whereas the NDVI was positively associated with the LW width of both species but such correlations were observed on May $(r=0.59, P=0.043)$ and September $(r=0.58, P=0.046)$ for $P$. halepensis and $P$. pinea, respectively (Fig. 3).

In P. halepensis we found positive and significant relationship of EW width index with the SPI at time scales 3 and 4 months $(r=0.31, P=0.018 ; r=0.28, P=0.029$, respectively) on August and at time scales 4 and 5 months on September $(r=0.29, P=0.025 ; r=0.31, P=0.019$, respectively) (Fig. 1, 4). The LW width showed high association with the SPI at time scales up to 4 months, from August to September, with the strongest response observed at time scale of 3 months $(r=0.39, P=0.003)$, on September. The RW showed a similar response pattern to the SPI as the LW did. However, in the case of RW the response to drought was somehow lower $(r=0.32, P=$ 0.015; time scale 4 months) compared to the LW width. A higher response of all wood components to drought was observed when the SPEI drought index was considered. The response of EW width 
211 to the SPEI was significant at time scales from 3 to 6 months, during July - September, with 212 maximum correlation values $(r=0.33, P=0.012)$ obtained at time scale of 5 months, on 213 September. The LW width and RW also responded significantly to the SPEI at time scales up to 5 214 and 6 months respectively (July - September). However, the highest drought impact (LW: $r=0.43$, $215 P<0.001$; RW: $r=0.33, P=0.010$ ) was observed on September, at the time scale of 2 and 4 216 months, respectively.

In $P$. pinea we observed a quite different pattern concerning the response of wood components to the drought indices as compared to P. halepensis (Fig. 1, 4). Both drought indices showed significant impacts only on EW width whereas no significant relationship was observed with LW width and RW. The EW width responded significantly to the SPI at time scale of 1 month on April $(r=0.28, P=0.032)$ and to the SPEI at time scales of 1 month on April $(r=0.31, P=$ 0.017), 9 months on June - July $(r=0.28, P=0.034 ; r=0.27, P=0.038$, respectively) and 10 months on July $(r=0.28, P=0.034)$.

\section{Discussion}

226 This study provides useful information on the reaction of tree radial growth and vegetation activity to climate variability in a region where dendroecological studies are scarce. In particular, the research was focused on the impact of climate and drought on vegetation activity and tree radial growth of two Mediterranean pine species, Pinus halepensis and P. pinea.

The vegetation indices representing the vegetation activity of $P$. halepensis and $P$. pinea mixed stand were significantly affected by the climatic drivers, particularly the EVI. This confirms the greater capacity of EVI to capture more variability in vegetation activity and amplify the vegetation signal in dense forests (Vacchiano et al. 2012; Garbulsky et al. 2013). Both indices were associated negatively and significantly with high temperatures on August, showing reduction of 235 photosynthetic activity under warming induced drought stress. This is also confirmed by the 236 significant positive association found between vegetation indices and tree radial growth on August, 
237 particularly in $P$. halepensis, indicating a link between site level tree growth and space-based 238 measurements of vegetation activity as found elsewhere (Wu et al. 2012; Dorman et al. 2013; Bunn 239 et al. 2013). The higher vegetation indices - radial growth correlations observed in the case of $P$. 240 halepensis as compared to $P$. pinea could be explained by the fact that $P$. halepensis is the dominant 241 species in the study area and the vegetation indices represent mostly the photosynthetic activity of 242 its individuals. The positive association of September precipitation with EVI shows that wet 243 conditions favour photosynthetic activity and tree growth in pine forests, after the drought control 244 of vegetation activity during summer months. As a matter of fact, both vegetation indices were 245 markedly affected by the SPI drought indices on August, period in which we observed the strongest 246 impact of drought on tree radial growth and the highest association of vegetation indices with tree radial growth. These findings confirm that drought determines to a large extend the vegetation activity and tree growth in periods when water demand is high (Dorman et al. 2013; VicenteSerrano et al. 2013; Maselli et al. 2014).

Both drought indices (SPI, SPEI) calculated at cumulative time scales were able to capture the drought impacts on tree growth and identify the time scale and season the growth mostly 252 responded to drought stress. This evidence emphasizes the usefulness of multi scalar drought 253 indices for monitoring impacts on tree growth as found for other systems (Vicente-Serrano et al. 2012). However, both species showed some differences in terms of vulnerability to SPI and SPEI, being more responsive to the latter drought index, particularly during summer months. This fact suggests that climate warming is affecting tree growth in the study area as found for other parts of the Mediterranean region (Sarris et al. 2011; Piraino et al. 2013; Granda et al. 2013; Mazza and 258 Manetti 2013; Nabais et al. 2014; Dorman et al. 2015). Considering that climate projections predict 259 an intensification of warming processes in the Mediterranean region (IPCC 2013), the SPEI drought 260 index seems to be more appropriate than the SPI at quantifying drought severity and impacts on tree 261 growth. 
The analysis revealed that warming-induced drought stress affected both species growing

under Mediterranean climate conditions. However, the response to drought indices was higher and observed at shorter time scales in $P$. halepensis as compared to $P$. pinea trees which responded mostly to mid-term drought stress (8-10 months). This suggests that patterns of forest response to drought are highly complex even at local scales and between co-existing species, and that drought time scale is relevant for capturing the delayed response of tree growth to drought stress. Similar results are obtained from previous studies on co-occurring low elevation Mediterranean pine species suggesting that climate-growth responses are species-specific (de Luis et al. 2009; SánchezSalguero et al. 2010; Novak et al. 2011; Nabais et al. 2014; Toromani et al. 2015a).

Although $P$. halepensis is considered as drought-avoiding species which may decrease transpiration by rapid stomata closure (Borghetti et al. 1998; Klein et al. 2011; Dorman et al. 2015), its inter-annual growth seems to be vulnerable to drought stress in summer-early autumn, leading to growth decline. This is in line with previous studies carried out on this species suggesting a significant impact of climate variability on $P$. halepensis growth across the Mediterranean region (Sánchez-Salguero et al. 2010, 2012; Sarris et al. 2011; Novak et al. 2011; Pasho et al. 2011; Dorman et al. 2015). The drought stress impacted the components of tree-ring in the short and midterms, particularly LW production in $P$. halepensis. This finding is related to high temperatures during summer and early autumn which affected negatively the tree growth in this species (Toromani et al. 2015a). Summer drought can reduce the hydraulic conductivity and photosynthesis in $P$. halepensis, which decreases the EW growth and the supply of carbohydrates for LW formation in late summer-early autumn (Camarero et al. 2010; Pasho et al. 2012; Sánchez-Salguero et al. 2012).

$P$. pinea trees (EW width) showed significant but lower vulnerability to drought stress during summer as compared to $P$. halepensis trees. Previous studies emphasized that the differing behavior to climatic variability of this species is probably related to its physiological characteristics such as the differing hydraulic architecture, lower susceptibility to cavitation and higher water use 
involved the age of trees in the attempts to explain climate-growth relationships in $P$. pinea (de Luis et al. 2009; Olivar et al. 2012; Mazza and Manetti 2013; Toromani et al. 2015a). These studies emphasized that old trees are less sensitive to drought conditions as opposed to the young ones since they reach more water from deeper soil layers and, therefore, show lower dependence on variations in soil water availability. This implies the existence of different growth strategies not only between species but also between trees of different ages, despite the fact that they grow in a common environment with common climate conditions. As a matter of fact, $P$. pinea trees in the study area are older (Fig. 1) and probably with a deeper root system than those of $P$. halepensis. In addition, the underground water table is affected by phreatic waters which compensate to some extent for the low summer precipitation and therefore might weaken the relation of tree growth with climatic parameters, as found elsewhere (Valladares et al. 2005). All these physiological-age-site characteristics might have mitigated the impact of water shortage events on $P$. pinea growth and 301 allowed it to maintain relatively high growth rates while experiencing moderate water stress. 302 Consequently, to be highly affected by drought this species must be exposed to water deficits that 303 are sustained over time, which require conditions that correspond to mid time scales of drought. In Albania dendrochronological studies are rather scarce and focused mostly on high-elevation species. For example, Seim et al. (2010) showed the potential of Pinus heldreichii tree-ring chronologies for climate reconstruction in Albania whereas Seim et al. (2012) demonstrated that tree-ring formation in Pinus heldreichii depends on summer precipitation and temperature. Pasho et al. (2014) found that tree-ring wood components in Abies borisii-regis responded significantly to drought at short cumulative time scales ( $<4$ months) in late summer-early autumn, particularly the

310 LW width. Levanic et al. (2014) used the tree-ring widths of Pinus nigra from five locations to 311 reconstruct the early summer temperatures in Albania. Toromani et al. (2015a) found that January 312 temperatures and September precipitation are very important for $P$. pinea radial growth and that $P$. 313 halepensis is mostly affected by the summer-early autumn climate conditions. Therefore, our 
314 investigation contributes bridging a gap on the map of tree-ring studies in the Mediterranean, a 315 region particularly vulnerable to climate variability.

316 In conclusion, temperature-induced drought stress and diminishing precipitation appeared to 317 become increasingly limiting for $P$. halepensis and to a lower extend for $P$. pinea trees, exerting a 318 great impact on radial growth and vegetation activity in these stands. The predicted warmer and 319 drier conditions in the region (Bruci 2007) will likely pose severe threats to these species, triggering 320 the decline of vegetation activity and tree radial growth. Therefore, the information provided in this 321 study should be useful for the early detection of forest dieback in Albania and to adapt appropriate 322 management strategies to mitigate the impacts of drought on P. halepensis and P. pinea growth.

\section{Acknowledgements}

329 The authors thank E. Toromani for his support related to the samples collection. Additional thanks go to S. Beqo and A. Buzali for their assistance related to the samples preparation. The constructive

331 comments of two anonymous referees related to the improvement of the manuscript are gratefully 332 acknowledged. 


\section{References}

Allen, C.D., Macalady, A.K., Chenchouni, H., Bachelet, D., McDowell, N., Vennetier, M., Kitzberger, T., Rigling, A., Breshears, D.D., Hogg, E.H. (Ted), Gonzalez, P., Fensham, R., Zhang, Z., Castro, J., Demidova, N., Lim, J.H., Allard, G., Running, S.W., Semerci, A., and Cobb, N. 2010. A global overview of drought and heat-induced tree mortality reveals emerging climate change risks for forests. For. Ecol. Manag. 259(4): 660-684. doi:10.1016/j.foreco.2009.09.001.

Borghetti, M., Cinnirella, S., Magnani, F., and Saracino, A. 1998. Impact of long-term drought on xylem embolism and growth in Pinus halepensis Mill. Trees 12(4): 187-195. doi:10.1007/PL00009709.

Bruci, E. 2007. Climate Change Projection for South Eastern Europe. HMI, Tirana Polytechnic University, Tirana, Albania. 67 pp.

Bunn, A.G., Hughes, M.K., Kirdyanov, Losleben, M., Shishov, V.V., Berner, L.T., Oltchev, A., and Vaganov, E.A. 2013. Comparing forest measurements from tree rings and a space-based index of vegetation activity in Siberia. Environ. Res. Lett. 8(3)doi:10.1088/17489326/8/3/035034.

Camarero, J.J., Olano, J.M., and Parras, A. 2010. Plastic bimodal xylogenesis in conifers from continental Mediterranean climates. New Phytol. 185(2): 471-480. doi: 10.1111/j.14698137.2009.03073.x.

Campelo, F., Nabais, C., Freitas, H., and Gutiérrez, E. 2007. Climatic significance of tree-ring width and intra-annual density fluctuations in Pinus pinea from a dry Mediterranean area in Portugal. Ann. For. Sci. 64(2): 229-238. doi: 10.1051/forest:2006107.

Cherubini, P., Gartner, B.L., Tognetti, R., Braker, O.U., Schoch, W., and Innes, J.L. 2003. Identification, measurement and interpretation of tree-rings in woody species from mediterranean climates. Biol. Rev. 78(1): 119-148. doi: 10.1017/S1464793102006000. 
Cook, E.R., and Peters, K. 1981. The smoothing spline: a new approach to standardizing forest interior tree-ring width series for dendroclimatic studies. Tree-Ring Bull. 41: 45-53.

Cook, E.R., and Holmes, R.L. 1984. Program ARSTAN user's manual. Laboratory of Tree Ring Research, University of Arizona, Tucson, USA.

Cook, E.R., and Kairiukstis, L.A. (eds) 1990. Dendrochronology: applications in the environmental sciences. Kluwer Academic Publishers, Doredrecht.

de Luis, M., Novak, K., Čufar, K., and Raventós, J. 2009. Size mediated climate-growth relationships in Pinus halepensis and Pinus pinea. Trees 23(5): 1065-1073. doi:10.1007/s00468-009-0349-5.

de Luis, M., Novak, K., Raventós, J., Gricar, J., Prislan, P., and Čufar, K. 2011. Climate factors promoting intra-annual density fluctuations in Aleppo pine (Pinus halepensis) from semiarid sites. Dendrochronologia 29(3): 163-169. doi:10.1016/j.dendro.2011.01.005

de Luis, M., Čufar, K., Di Filippo, A., Novak, K., Papadopoulos, A., Piovesan, G.,Rathgeber, C.B., Raventos, J., Saz, M.A., and Smith, K.T. 2013. Plasticity in dendroclimatic response across the distribution range of Aleppo pine (Pinus halepensis). PLoS ONE 8(12): 119-148. doi:10.1371/journal.pone.0083550.

Dorman, M., Svoray, T., Perevolotsky, A., and Sarris D. 2013. Forest performance during two consecutive drought periods: Diverging long-term trends and short-term responses along a climatic gradient. Forest Ecol. Manag. 310: 1-9. doi:10.1016/j.foreco.2013.08.009.

Dorman, M., Perevolotsky, A., Sarris, D., and Svoray, T. 2015. The effect of rainfall and competition intensity on forest response to drought: lessons learned from a dry extreme. Oecol. 177(4): 1025-1038. doi 10.1007/s00442-015-3229-2.

Fritts, H.C. 1976. Tree Rings and Climate. Academic Press, London, pp. 567.

Gao, X., Huete, A.R., Ni, W., and Miura, T. 2000. Optical-biophysical relationships of vegetation spectra without background contamination. Remote Sens. Environ. 74(3): 609-620. doi:10.1016/S0034-4257(00)00150-4. 
Garbulsky, M.F., Peñuelas, J., Ogaya, R., and Filella, I. 2013. Leaf and stand-level carbon uptake of a Mediterranean forest estimated using the satellite-derived reflectance indices EVI and PRI. Int. J. Remote Sens. 34(4): 1282-1296. doi: 10.1080/01431161.2012.718457.

García-Ruiz, J.M., López-Moreno, J.I., Vicente-Serrano, S.M., Lasanta-Martínez, T., and Beguería, S. 2011. Mediterranean water resources in a global change scenario. Earth-Sci. Rev. 105(34):121-139. doi: 10.1016/j.earscirev.2011.01.006.

Granda, E., Camarero, J.J., Gimeno, T.E., Martínez-Fernández, J., and Valladares, F. 2013. Intensity and timing of warming and drought differentially affect growth patterns of cooccurring Mediterranean tree species. Eur. J. For. Res. 132(3): 469-480. doi: 10.1007/s10342-013-0687-0.

Holmes, R.L. 1983. Computer-assisted quality control in tree ring dating and measurement. TreeRing Bull. 43: 69-78.

Huete, A., Didan, K., Miura, T., Rodriguez, E.P., Gao, X., and Ferreira, L.G. 2002. Overview of the radiometric and biophysical performance of the MODIS vegetation indices. Remote Sens. Environ. 83(1-2): 195-213. doi: 10.1016/S0034-4257(02)00096-2. IPCC, 2013. Climate change 2013: the physical science basis. Contribution of Working Group I to the fifth assessment report of the Intergovernmental Panel on Climate Change. Cambridge University Press, Cambridge (UK).

Klein, T., Cohen, S., and Yakir, D. 2011. Hydraulic adjustments underlying drought resistance of Pinus halepensis. Tree Physiol. 31(6): 637-648. doi:10.1093/treephys/tpr047.

Klein, T., Di Matteo, G., Rotenberg, E., Cohen, S., and Yakir, D. 2013. Differential ecophysiological response of a major Mediterranean pine species across a climatic gradient. Tree Physiol.33(1):26-36. doi:10.1093/treephys/tps116.

Klein, T., Hoch, G., Yakir, D., and Körner, C. 2014. Drought stress, growth and nonstructural carbohydrate dynamics of pine trees in a semi-arid forest. Tree Physiol. 34(9): 981-992. doi:10.1093/treephys/tpu071. 
Koepke, D.F., Kolb, T.E., and Adams, H.D. 2010. Variation in woody plant mortality and dieback from severe drought among soils, plant groups, and species within a northern Arizona ecotone. Oecologia 163(4): 1079-1090. doi: 10.1007/s00442-010-1671-8.

Leone, V., Marchiori, S., Colacino, C., Fascetti, S., Medagli, P., Saracino, A., and Temerari, P. 2003. Habitat della laguna di Karavasta e delle zone contermini: considerazioni e restauro. In: Balda ssarre, G. (ed.), Salvaguardia e sviluppo sostenibile dell'area lagunare di Karavasta (Albania). Atti del Seminario: Divjaka (Albania). Universita di Bari (Edizioni dal Sud), Bari. Pp. 55-65.

Levanič, T., Poljanšek, S., and Toromani, E. 2014. Early summer temperatures reconstructed from black pine (Pinus nigra Arnold) tree-ring widths from Albania. Holocene 25(3): 469-481. doi: $10.1177 / 0959683614561882$.

Maselli, F., Cherubini, P., Chiesi, M., Gilabert, M.A., Lombardi, F., Moreno, A., Teobaldelli, M., and Tognetti, R. 2014. Start of the dry season as a main determinant of inter-annual Mediterranean forest production variations. Agric. For. Meteorol. 194:197-206. doi: 10.1016./j.agrformet.2014.04.006.

Mazza, G., and Manetti, M. C. 2013. Growth rate and climate responses of Pinus pinea L. in Italian coastal stands over the last century. Clim. Chang. 121(4): 713-725. doi: 10.1007/s10584013-0933-y.

McKee, T.B.N., Doesken, J., and Kleist, J. 1993. The relationship of drought frequency and duration to time scales. In Eight Conference on Applied Climatology. American Meteorological Society, Anaheim, California. pp. 179-184.

Miho, A., and Witkowski, A. 2005. Diatom (bacillariophyta) flora of Albanian coastal wetlands. Taxonomy and ecology: Proc. Calif. Acad. Sci. 56(12): 129-145.

Nabais, C., Campelo, F., Vieira, J., and Cherubini, P. 2014. Climatic signals of tree-ring width and intra-annual density fluctuations in Pinus pinaster and Pinus pinea along a latitudinal gradient in Portugal. Forestry 87: 598-605. doi:10.1093/forestry/cpu021. 
Novak, K., de Luis, M., Čufar, K., and Raventós, J. 2011. Frequency and variability of missing tree rings along the stems of Pinus halepensis and Pinus pinea from a semiarid site in SE Spain. J. Arid Environ. 75(5): 494-498. doi: 10.1016/j.jaridenv.2010.12.005.

Novak, K., Sánchez, M. A., Čufar, K., Raventós, J., and de Luis, M. 2013. Age, climate and intraannual density fluctuations in Pinus halepensis in Spain. IAWA J. 34(4): 459-474. doi:10.1163/22941932-00000037.

Olivar, J., Bogino, S., Spiecker, H., and Bravo, F. 2012. Climate impact on growth dynamic and intra-annual density fluctuations in Aleppo pine (Pinus halepensis) trees of different crown classes. Dendrochronologia 30: 35-47. doi:10.1016/j.dendro.2011.06.001.

Oliveras, I., Martínez-Vilalta, J., Jimenez-Ortiz, T., Lledó, M.J., Escarré, A., and Piñol, J. 2003. Hydraulic properties of Pinus halepensis, Pinus pinea and Tetraclinis articulata in a dune ecosystem of Eastern Spain. Plant Ecol. 169(1): 131-141. doi: 10.1023/A:1026223516580.

Paparisto, K., Demiri, M., Mitrushi, I., and Qosja, X. 1988. Flora e Shqiperise. Vol. 1. Akademia e Shkencave e RPS te Shqiperise. Qendra e Kerkimeve Biologjike, pp. 457. Tirana.

Pasho, E., Camarero, J.J., de Luis, M., and Vicente-Serrano, S.M. 2011. Impacts of drought at different time scales on forest growth across a wide climatic gradient in north-eastern Spain. Agric. For. Meteorol. 151(12): 1800-1811. doi: 10.1016/j.agrformet.2011.07.018.

Pasho, E., Camarero, J.J., and Vicente-Serrano, S.M. 2012. Climatic impacts and drought control of radial growth and seasonal wood formation in Pinus halepensis. Trees 26(6): 1875-1886. doi:10.1007/s00468-012-0756-X.

Pasho, E., Toromani, E., and Alla, A.Q. 2014. Climatic impact on tree-ring widths in Abies borisiiregis forests from South-East Albania. Dendrochronologia 32(3): 237-244. doi:10.1016/j. dendro.2014.05.003

Piraino, S., Camiz, S., Di Filippo, A., Piovesan, G., and Spada, F. 2013. A dendrochronological analysis of Pinus pinea L. on the Italian mid-Tyrrhenian coast. Geochronometria 40(1): 7789. doi: 10.2478/s13386-012-0019-z. 
Raventós, J., de Luís, M., Gras, M., Cufar, K., González-Hidalgo, J., Bonet, A., and Sánchez, J. 2001. Growth of Pinus pinea and Pinus halepensis as affected by dryness, marine spray and land use changes in a Mediterranean semiarid ecosystem. Dendrochronologia 19(2): 211220.

Sánchez-Costa, E., Poyatos, R., and Sabaté, S. 2015. Contrasting growth and water use strategies in four co-occurring Mediterranean tree species revealed by concurrent measurements of sap flow and stem diameter variations. Agric. For. Meteorol. 207: 24-37. doi: 10.1016/j.agrformet.2015.03.012.

Sánchez-Salguero, R., Navarro, R.M., Camarero, J.J., and Fernández-Cancio, Á. 2010. Droughtinduced growth decline of Aleppo and maritime pine forests in south-eastern Spain. For. Syst. 19(3): 458-470. doi: 10.5424/fs/2010193-9131.

Sánchez-Salguero, R., Navarro-Cerrillo, R.M., Camarero, J.J., and Fernández-Cancio, Á. 2012.Selective drought-induced decline of pine species in southeastern Spain. Clim. Chang. 113(3-4):767-785. doi: 10.1007/s10584-011-0372-6.

Sarris, D., Christodoulakis, D., and Körner, C. 2011. Impact of recent climatic change on growth of low elevation eastern Mediterranean forest trees. Clim. Change 106(2): 203-223. doi:10.1007/s10584-010-9901-y.Seim, A., Treydte, K., Büntgen, U., Esper, J., Fonti, P., Haska, H., Herzig, F., Tegel, W., and Faust, D. 2010. Exploring the potential of Pinus heldreichii Christ. for long-term climate reconstruction in Albania. TRACE 8:75-82.

Seim, A., Büntgen, U., Fonti, P., Haska, H., Herzig, F., Tegel, W., Trouet, V., and Treydte, K. 2012. Climate sensitivity of a millennium-long pine chronology from Albania. Clim. Res. 51(3): 217-228. doi: 10.3354/cr01076.

Stokes, M., and Smiley, T. 1968. An introduction to tree ring dating. University of Chicago Press, Chicago.pp. 73. 
Toromani, E., Pasho, E., Alla, A.Q., Çollaku, N., and Mine, V. 2015a. Radial growth responses of Pinus halepensis Mill. and Pinus pinea L. forests to climate variability in western Albania. Geochronometria 42(1): 91-99. doi: 10.1515/geochr-2015-0012.

Toromani, E., Pasho, E., and Alla, A.Q. 2015b. Toromani - Divjaka - PIHA - ITRDB ALB004. Available from http://www.ncdc.noa.gaov/paleo/study/18955.

Toromani, E., Pasho, E., and Alla, A.Q. 2015c. Toromani - Divjaka - PIPN - ITRDB ALB005. Available from http://www.ncdc.noaa.gov/paleo/study/18956.

Tucker, C.J., Vanpraet, C.L., Sharman, M.J., and Van Ittersum, G. 1985. Satellite remote sensing of total herbaceous biomass production in the senegalese sahel: 1980-1984. Remote Sens. Environ. 17(3): 233-249. doi: 10.1016/0034-4257(85)90097-5.

Vacchiano, G., Garbarino, M., Borgogno Mondino, E., and Motta, R. 2012. Evidences of drought stress as a predisposing factor to Scots pine decline in Valle d'Aosta (Italy). Eur. J. For. Res. 131(4): 989-1000. doi: 10.1007/s10342-011-0570-9.

Valladares, F., Peñuelas, J., and de Luis, E. 2005. Impacts on terrestrial ecosystems. In A preliminary assessment of the impacts in Spain due to the effects of climate change. ECCE Project-Final report. Ministerio de Medio Ambiente, Madrid.

Vicente-Serrano, S.M. 2006. Differences in spatial patterns of drought on different time scales: an analysis of the Iberian Peninsula. Water Resour. Manag. 20(1): 37-60. doi: 10.1007/s11269006-2974-8.

Vicente-Serrano, S.M., Beguería, S., and López-Moreno, J.I. 2010. A multiscalar drought index sensitive to global warming: the standardized precipitation evapotranspiration index. J. Clim. 23(7): 1696-1718. doi: 10.1175/2009JCLI2909.1.

Vicente-Serrano, S.M., Beguería, S., Lorenzo-Lacruz, J., Camarero, J.J., López-Moreno, J.I., Azorin-Molina, C., Revuelto, J., Morán-Tejeda, E., and Sanchez-Lorenzo, A. 2012. Performance of drought indices for ecological, agricultural, and hydrological applications. Earth Interact. 16(10): 1-27. doi: 10.1175/2012EI000434.1. 
Vicente-Serrano, S.M., Gouveia, C., Camarero, J.J., Beguería, S., Trigo, R., López-Moreno, J.I., Azorín-Molina, C., Pasho, E., Lorenzo-Lacruz, J., Revuelto, J., Morán-Tejeda, E., and Sanchez-Lorenzo, A. 2013. Response of vegetation to drought time-scales across global land biomes. Proc. Natl. Acad. Sci. U.S.A. 110(1): 52-57. doi: 10.1073/pnas.1207068110.

Vieira, J., Campelo, F., and Nabais, C. 2010. Intra-annual density fluctuations of Pinus pinaster are a record of climatic changes in the western Mediterranean region. Can. J. For. Res. 40(8):1567-1575. doi: 10.1139/X10-096.

Wang, J., Rich, P.M., Price, K.P., and Kettle, W.D., 2004. Relations between NDVI and tree productivity in the central Great Plains. Int. J. Remote Sens. 25(16): 3127-3138. doi:10.1080/0143116032000160499.

Wardlow, B.D., Egbert, S.L., and Kastens, J.H. 2007. Analysis of time-series MODIS $250 \mathrm{~m}$ vegetation index data for crop classification in the U.S. Central Great Plains. Remote Sens. Environ. 108(3): 290-310. doi: 10.1016/j.rse.2006.11.021.

Wigley, T.M.L., Briffa, K.R., and Jones, P.D. 1984. On the average value of correlated time-series, with applications in dendroclimatology and hydrometeorology. J. Clim. Appl. Meteorol. 23(2): 201-213. doi: 10.1175/1520-0450(1984) 023<0201: OTAVOC $>2.0$. CO;2.

Wu, C., Chen, J. M., Desai, A. R., Hollinger, D. Y., Arain, M. A., Margolis, H. A., Gough, C.M., and Staebler, R.M. 2012. Remote sensing of canopy light use efficiency in temperate and boreal forests of North America using MODIS imagery. Remote Sens. Environ. 118: 60-72. doi:10.1016/j.rse.2011.11.012.

Zdruli, P., 1997. Benchmark Soils of Albania: Soil and site characteristics. Agricultural University of Tirana, Albania. 


\section{Figure captions:}

Figure 1. Mean tree-ring residual chronologies (EW, LW and RW) of P. halepensis and $P$. pinea (grey lines) and the evolution of the drought indices (SPI, SPEI) (coloured lines) at the cumulative time scales ( $P$. halepensis: SPI and SPEI, time scale of 3 months on August and September, respectively; $P$. pinea: SPI and SPEI, on July at the time scale of 9 and 10 months, respectively. See Fig. 4) at which radial growth series responded mostly to the drought indices. Note that raw treering chronologies (all samples) can be found at Toromani et al. (2015a).

Figure 2. Relationships of the vegetation indices (NDVI and EVI) with climate (temperature and precipitation) and the drought indices (SPI and SPEI) at the time scale of 1 month.

Figure 3. Relationships between EW, LW and RW residual chronologies of $P$. halepensis and $P$. pinea, and the vegetation indices (NDVI, EVI).

Figure 4. Correlation coefficients between EW, LW and RW residual chronologies and the SPI, SPEI drought indices calculated at cumulative time scales (1-12 months) from January up to December, for the two studied species. Colours indicate different correlation coefficients (see the legend). Bold solid lines frame significant correlations $(P<0.05)$. 


\section{List of figures:}

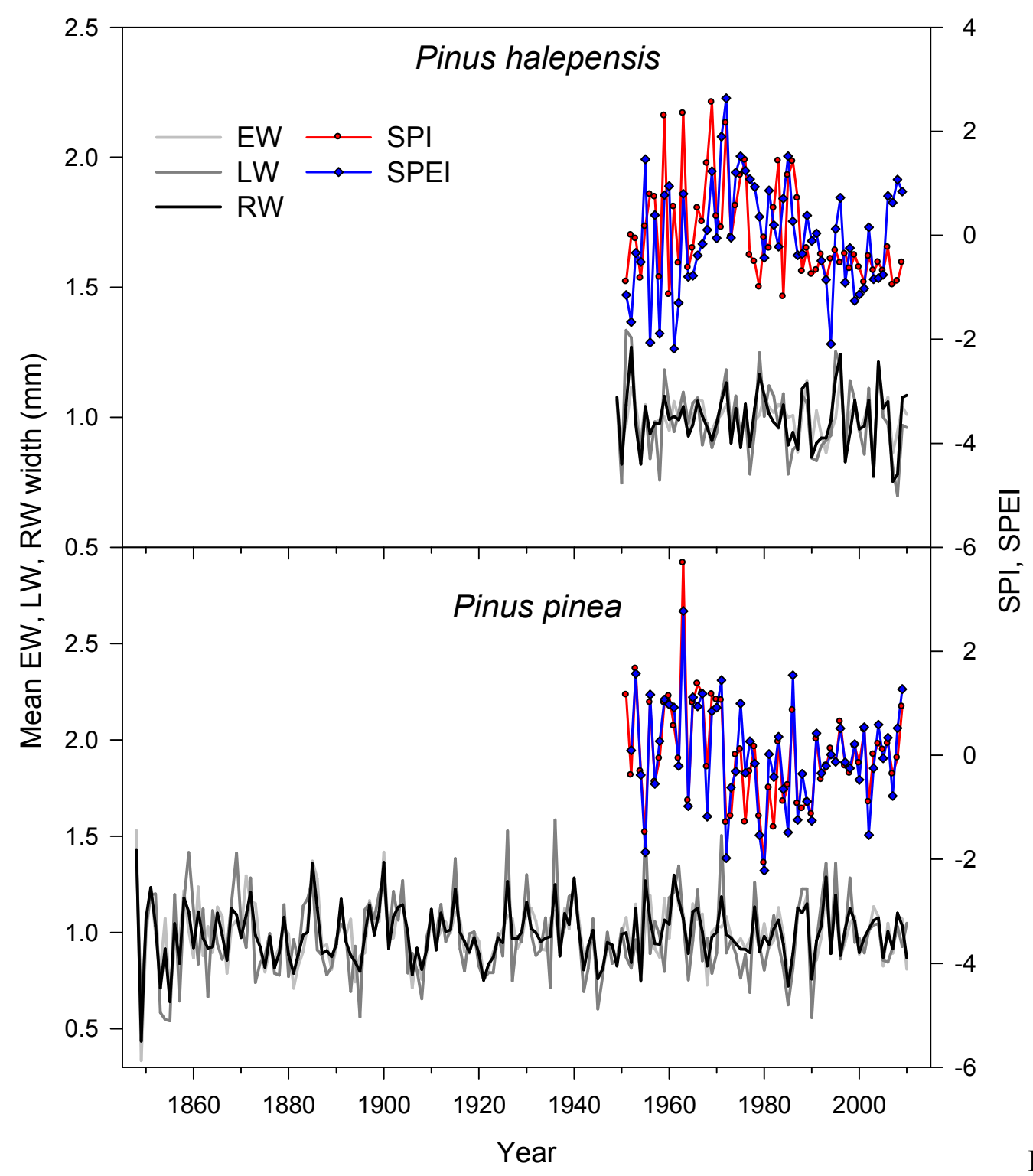

Figure 1. 


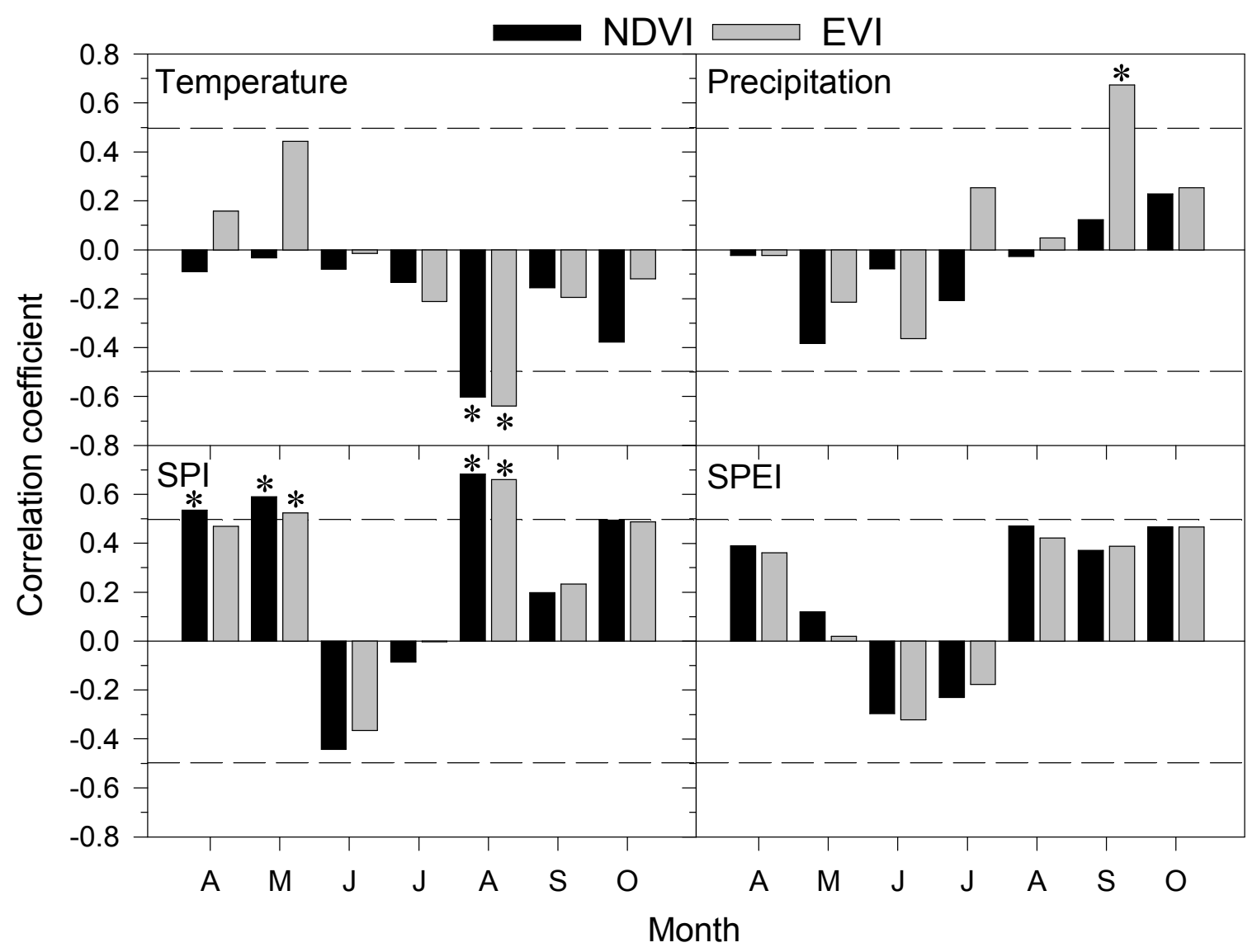

Figure 2. 


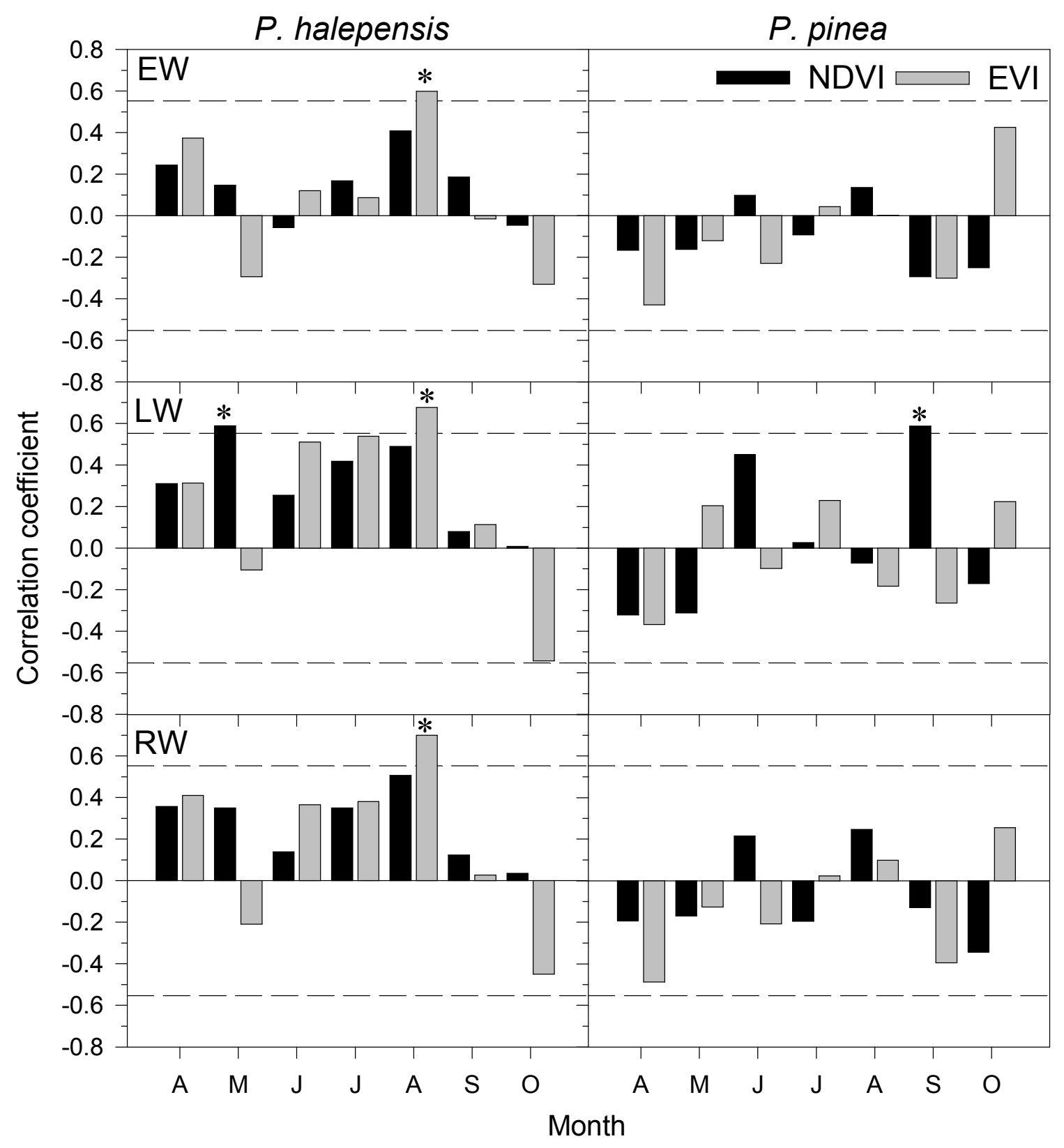

Figure 3. 

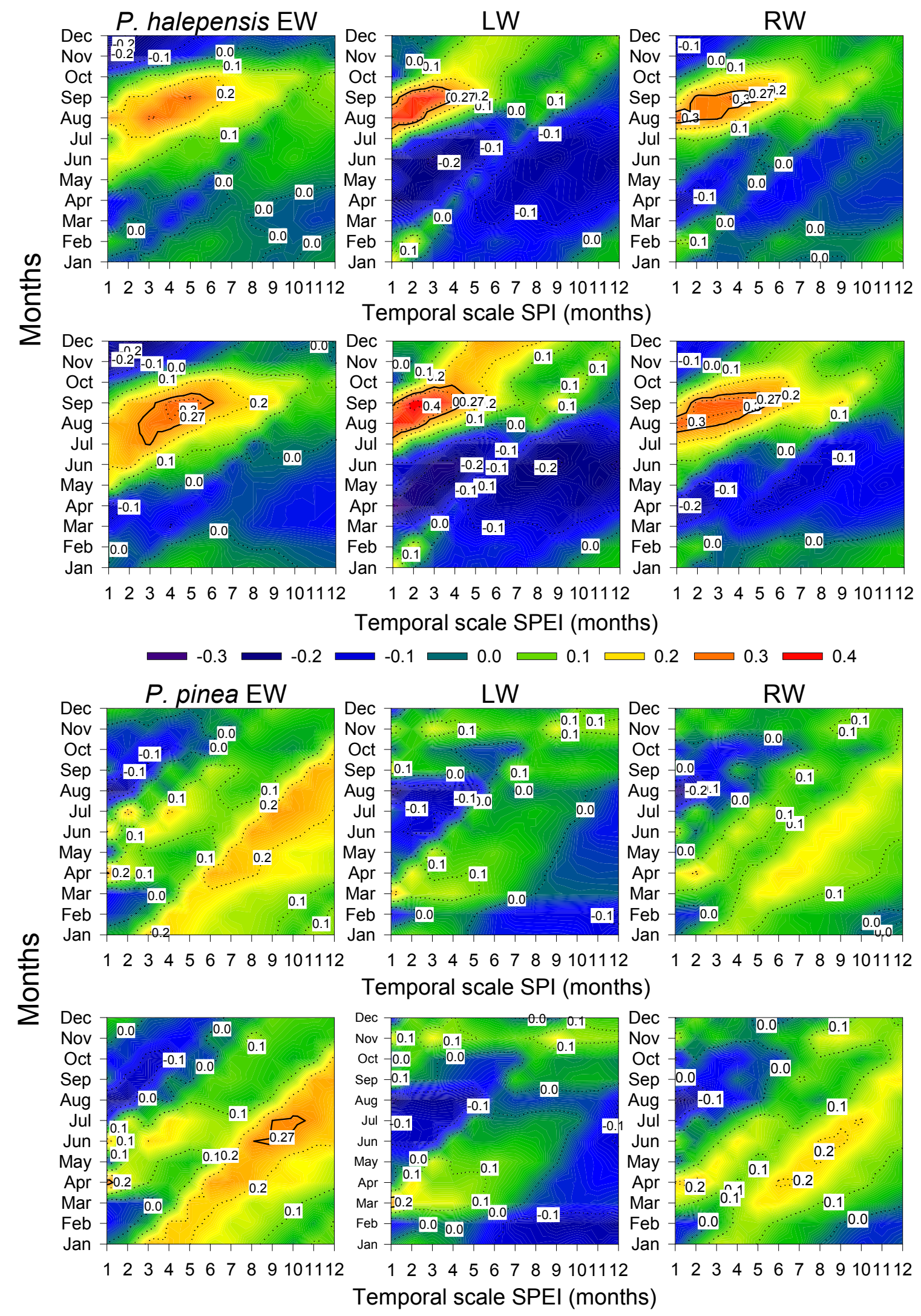

Figure 4. 